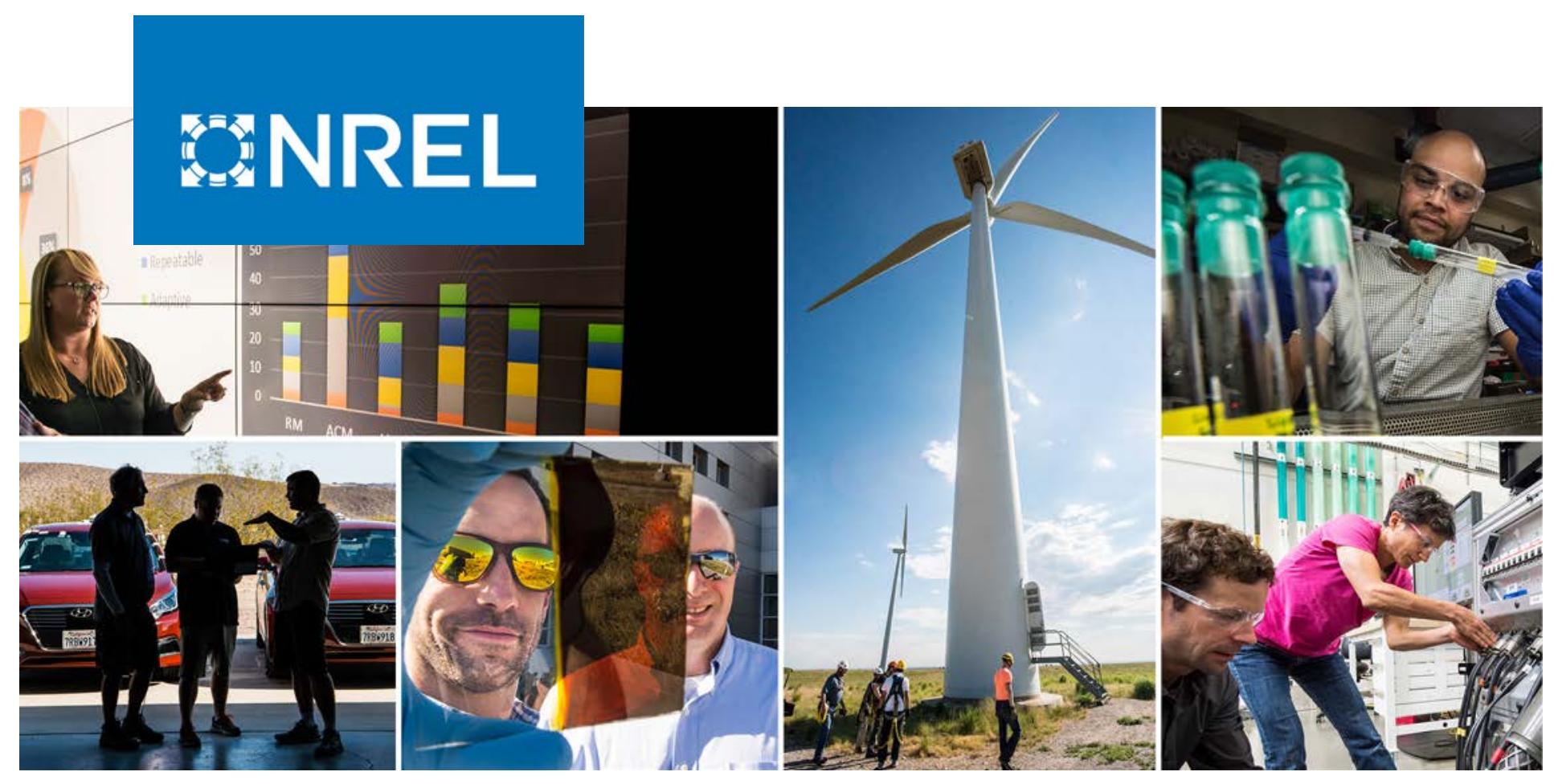

\title{
SolarAPP+ Pilot Analysis: Performance and Impact of Instant, Online Solar Permitting
}

Juliana Williams, Jeffrey J. Cook, Jesse R. Cruce, Kaifeng Xu, Seth Crew, Minahil Qasim, and Matt Miccioli

National Renewable Energy Laboratory

NREL is a national laboratory of the U.S. Department of Energy Office of Energy Efficiency \& Renewable Energy

Operated by the Alliance for Sustainable Energy, LLC

This report is available at no cost from the National Renewable Energy Laboratory (NREL) at www.nrel.gov/publications.
Technical Report

NREL/TP-6A20-81603

January 2022 


\title{
BNREL
}

\section{SolarAPP+ Pilot Analysis: Performance and Impact of Instant, Online Solar Permitting}

\author{
Juliana Williams, Jeffrey J. Cook, Jesse R. Cruce, \\ Kaifeng Xu, Seth Crew, Minahil Qasim, and Matt Miccioli \\ National Renewable Energy Laboratory
}

\section{Suggested Citation}

Williams, Juliana, Jeffrey J. Cook, Jesse R. Cruce, Kaifeng Xu, Seth Crew, Minahil Qasim, and Matt Miccioli. 2022. SolarAPP+ Pilot Analysis: Performance and Impact of Instant, Online Solar Permitting. Golden, CO: National Renewable Energy Laboratory. NREL/TP-6A20-81603 https://www.nrel.gov/docs/fy22osti/81603.pdf.

NREL is a national laboratory of the U.S. Department of Energy Office of Energy Efficiency \& Renewable Energy Operated by the Alliance for Sustainable Energy, LLC

This report is available at no cost from the National Renewable Energy Laboratory (NREL) at www.nrel.gov/publications.

Contract No. DE-AC36-08GO28308
Technical Report NREL/TP-6A20-81603 January 2022

National Renewable Energy Laboratory 15013 Denver West Parkway Golden, CO 80401 303-275-3000 • www.nrel.gov 


\section{NOTICE}

This work was authored by the National Renewable Energy Laboratory, operated by Alliance for Sustainable Energy, LLC, for the U.S. Department of Energy (DOE) under Contract No. DE-AC36-08GO28308. Funding provided by the U.S. Department of Energy Office of Energy Efficiency and Renewable Energy Solar Energy Technologies Office. The views expressed herein do not necessarily represent the views of the DOE or the U.S. Government.

This report is available at no cost from the National Renewable Energy Laboratory (NREL) at www.nrel.gov/publications.

U.S. Department of Energy (DOE) reports produced after 1991 and a growing number of pre-1991 documents are available free via www.OSTI.gov.

Cover Photos by Dennis Schroeder: (clockwise, left to right) NREL 51934, NREL 45897, NREL 42160, NREL 45891, NREL 48097, NREL 46526.

NREL prints on paper that contains recycled content. 


\section{Acknowledgments}

The authors would like to acknowledge the extensive collaboration from solar industry partners, jurisdictions, and supporting organizations that made this project possible. First, this project was conducted with the support and guidance of Andrew Graves, with the U.S. Department of Energy (DOE), Office of Energy Efficiency and Renewable Energy. The SolarAPP+ pilot would not have taken place without the dedication and effort of the SolarAPP+ development team. The authors are grateful for the time and energy pilot partners contributed to SolarAPP+ implementation and data collection: the City of Menifee, California; the City of Pleasant Hill, California; Pima County, Arizona; the City of Stockton, California; and the City of Tucson, Arizona. Additionally, the authors would like to thank the cities of Oceanside, California and Modesto, California for their engagement and input in the planning stage of the pilot. The authors recognize the collaboration from the partner contractors who helped make the pilot a success: Custom Solar and Leisure, Energy Service Partners, Freedom Forever, Net Zero Solar, New Day Solar, SolarMax, Solar Solution AZ, Solar Works, Solcius, Sunbright Solar, SunPower, Sunrun, Technicians for Sustainability, Tesla, The Solar Store, and Titan Solar Power. Finally, the authors are grateful for the feedback each of our reviewers provided on the draft report:

- Igor Tregub (California Solar and Storage Association)

- Gloria Alvarez (City of Menifee, CA)

- Geoffrey Simmons (City of Pleasant Hill, CA)

- John Schweigerdt (City of Stockton, CA)

- Clayton Trevillyan (City of Tucson, AZ)

- Daniel Ice (County of Pima, AZ)

- Richard Lawrence (Interstate Renewable Energy Council)

- Emily Fekete and Sushmita Jena (National Renewable Energy Laboratory)

- Evelyn Butler (Solar Energy Industries Association)

- Crescent Romero (SunPower)

- Kelly Rehm (Technicians for Sustainability)

- Eric Jung (Titan Solar Power)

- Abigail Randall (U.S. Department of Energy [DOE])

- Valerie Anderson (Tesla, Inc.). 


\section{List of Acronyms}

ACA

AHJ

DOE

IBC

IRC

NEC

NREL

PV

SolarAPP+
Accela Citizen Access

authority having jurisdiction

U.S. Department of Energy

International Building Code

International Residential Code

National Electric Code

National Renewable Energy Laboratory

photovoltaic

Solar Automated Permit Processing Plus 


\section{Executive Summary}

The rapid increase in residential solar photovoltaic (PV) adoption has challenged authorities having jurisdiction (AHJs) to keep pace with the higher volume of solar applications requiring review and approval. Permitting requirements and delays, paired with similar inspection- and interconnection-related delays, may lead to lower PV adoption rates both directly through higher costs and indirectly through negative customer experiences (Cook et al. 2021a; O'Shaughnessy et al. 2020; Sinitskaya et al. 2019; Wolske et al. 2020).

To address residential solar PV permitting resource constraints and streamline solar permitting processes among AHJs, the National Renewable Energy Laboratory (NREL) led a collaborative effort to develop the Solar Automated Permit Processing Plus (SolarAPP+), a solar permitting software solution provided at no cost to AHJs. The SolarAPP+ is an online portal that automates permit plan review, thereby enabling an instant permit approval process for code-compliant residential PV systems. Based on national model building, electrical, and fire codes, SolarAPP+ automatically performs a compliance check of permit inputs against code requirements and produces an inspection checklist that can be used to verify installation practices, workmanship, and adherence to the approved design.

NREL conducted a control trial pilot to validate SolarAPP+ performance, as used by AHJs with diverse characteristics and needs. Five AHJs were selected for the pilot: Menifee, California; Pima County, Arizona; Pleasant Hill, California; Stockton, California; and Tucson, Arizona. Highlights of key findings include:

- Pilot AHJs collectively spent 383 hours on SolarAPP+ implementation and saved 236 hours on permit and revision review during the course of the pilot.

- By providing instantaneous review, the SolarAPP+ reduced the average permit review time to less than one day across all five AHJs.

- Participating contractors required training on how to use the application efficiently.

- Inspection passage rates for SolarAPP+ projects were comparable to traditionally permitted projects, with nominal impacts on inspection duration.

- Projects submitted through SolarAPP+ were installed and inspected on average 12 days faster than projects using the traditional process (Figure ES- 1). 


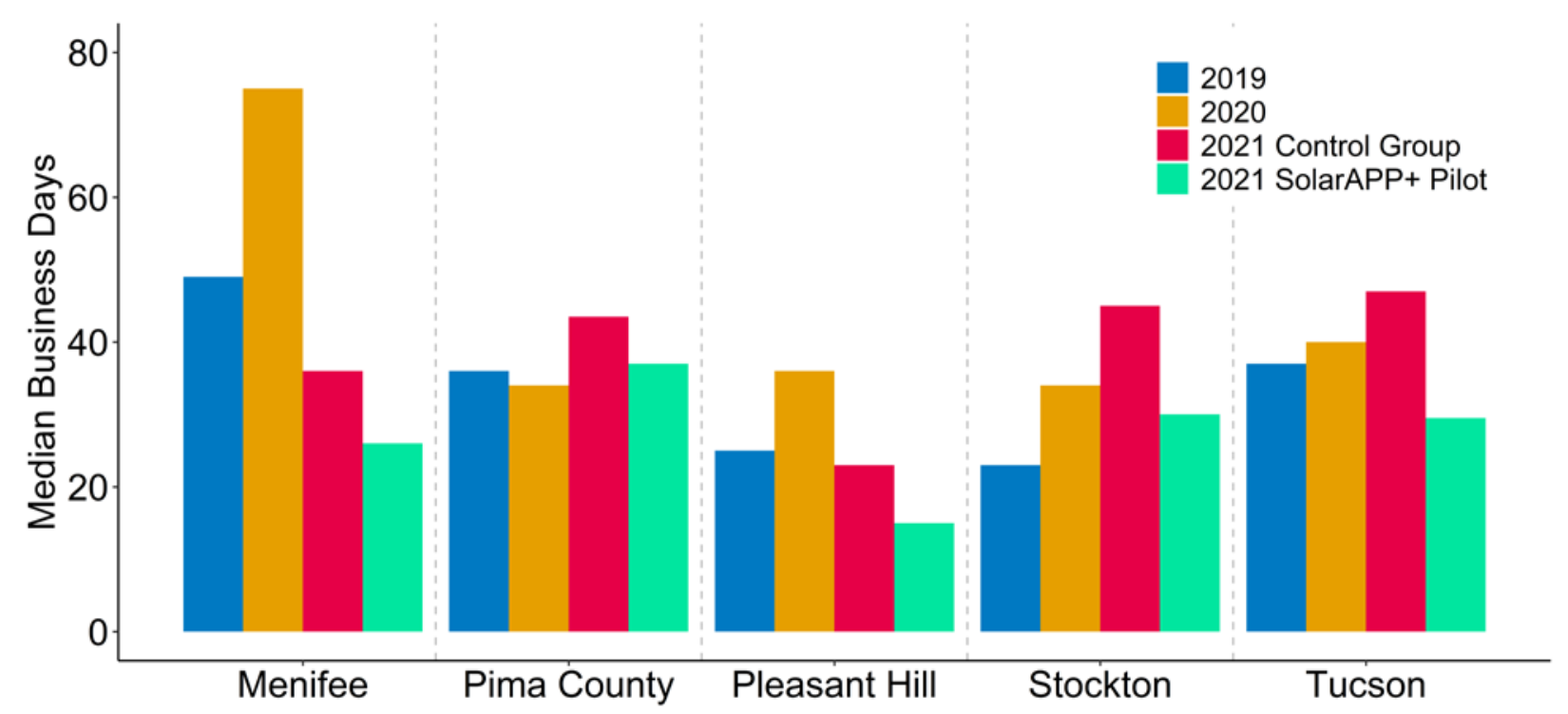

Figure ES- 1. Median project time from permit submission to passed inspection

Following the pilot, the AHJs rolled out SolarAPP+ to all local contractors, not just the contractors participating in the pilot. From the Pilot Closure to New Permits date through December 3, 2021, the AHJs saved over 2,500 additional staff hours on permit and revision review. 


\section{Table of Contents}

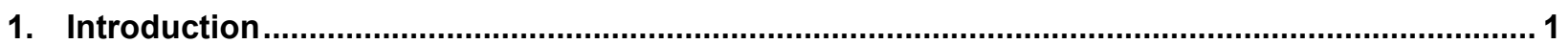

2. Traditional Permit Processing Meets the SolarAPP+ ........................................................... 2

2.1 Impacts of Permitting Review and Requirement Variation .............................................. 3

2.2 Instant Permitting Software and SolarAPP+ Development........................................................ 4

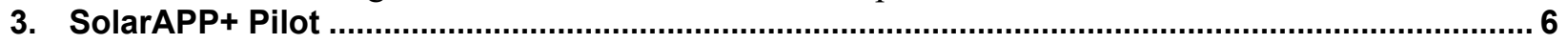

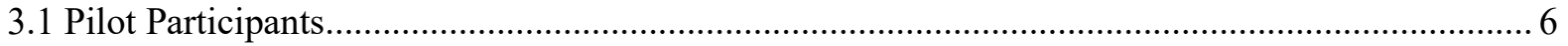

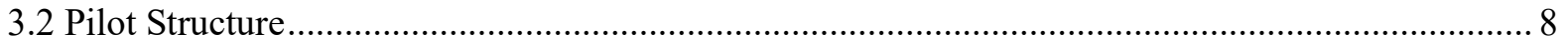

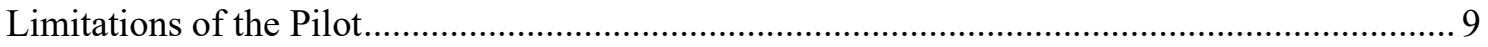

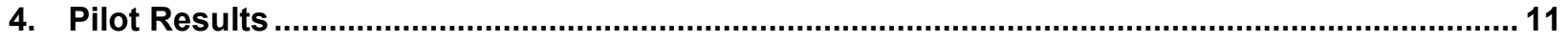

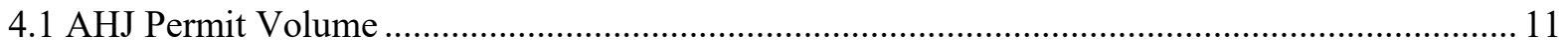

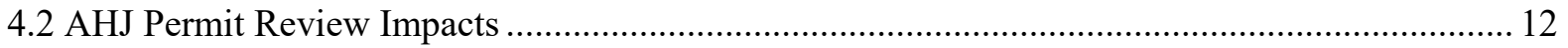

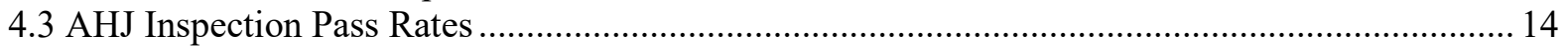

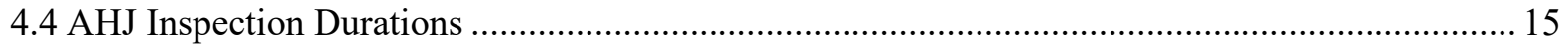

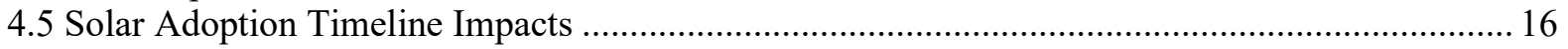

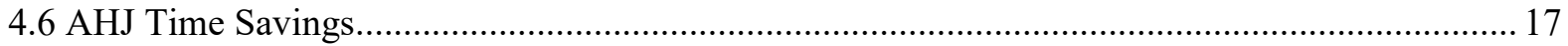

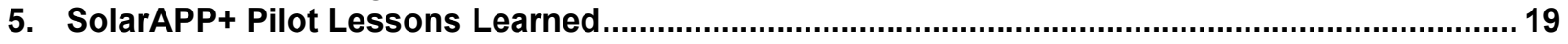

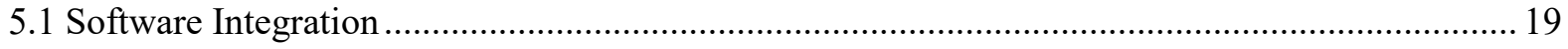

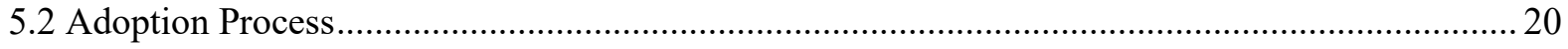

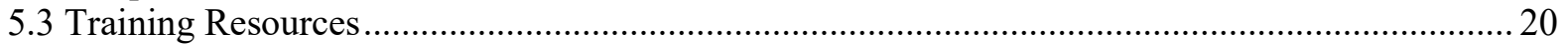

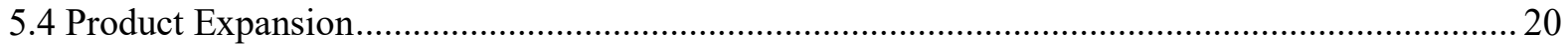

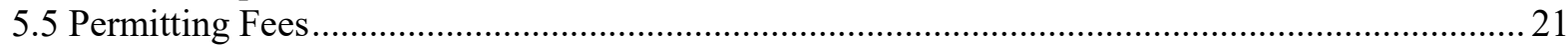

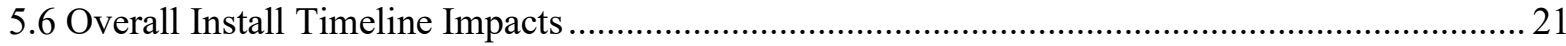

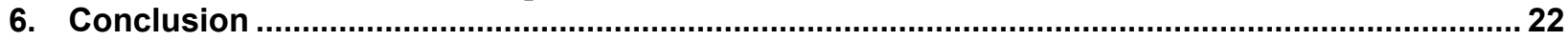

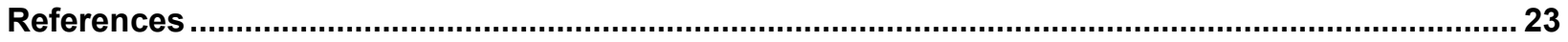

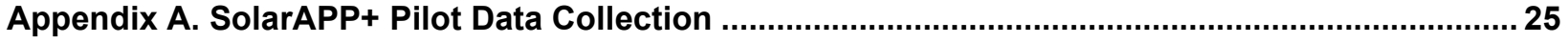




\section{List of Figures}

Figure ES- 1. Median project time from permit submission to passed inspection.......................................vi

Figure 1. The residential PV permitting process.............................................................................. 2

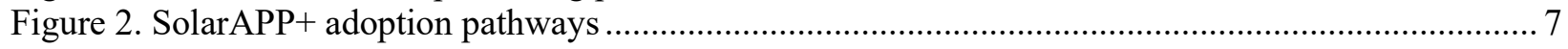

Figure 3. Median residential solar permit review time (business days) .................................................. 12

Figure 4. Frequency of permit revisions among SolarAPP+ projects across all AHJs ............................. 13

Figure 5. Reported causes of SolarAPP+ inspection failures, with avoidable failures in bold.................. 15

Figure 6. Mean inspection duration for control and SolarAPP+ projects ............................................ 16

Figure 7. Median project time from permit submission to passed inspection........................................... 17

\section{List of Tables}

Table 1. SolarAPP+ Pilot AHJ Characteristics by Phase and SolarAPP+ Adoption Pathway .................... 6

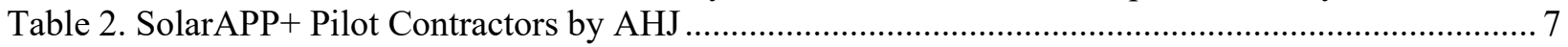

Table 3. Pilot Milestones, in Chronological Order of Launch.............................................................. 9

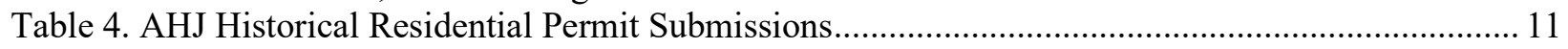

Table 5. Residential Solar Permit Submittals and Passed Inspections During Pilot................................ 11

Table 6. Historical and Pilot Inspection Failure Rates by AHJ ............................................................ 14

Table 7. Estimated AHJ Permit and Revision Review Time Savings During Pilot, in Hours................... 18

Table 8. Estimated AHJ Permit and Revision Review Time Savings Post-Pilot Through December 3,

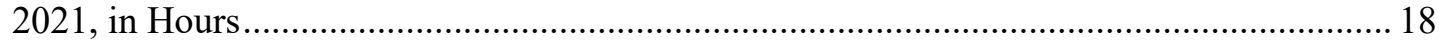




\section{Introduction}

The residential solar photovoltaic (PV) market in the United States has grown significantly over the last decade, with annual installations increasing from around 50,000 systems in 2010 to over 420,000 systems in 2020 (Davis et al. 2021a). Most of the 420,000 systems installed were required to apply for a building permit from one of over 20,000 United States authorities having jurisdiction (AHJs) prior to installation.

Nationally, both average and median permit review times are estimated to exceed 5 business days, and in certain jurisdictions they can stretch to a month or more (NREL 2021). Through 2030, residential solar installs are expected to grow 9\% to 12\% per year (Davis et al. 2021b), which could further impact resource-constrained AHJs and their related permit review timelines. At the same time, many residential solar systems are simple and standardized, allowing for software to automate the permitting process for those systems.

In collaboration with solar industry stakeholders, the National Renewable Energy Laboratory (NREL) led the effort to develop the Solar Automated Permit Processing Plus (SolarAPP+), a solution made available to AHJs at no cost to streamline their solar permitting processes. Planned expansions of SolarAPP+ functionality include providing automated permit plan review for technologies beyond solar, such as battery storage systems and electric vehicle charging stations. The SolarAPP+ is an online portal that automates permit plan review, thereby enabling an instant permit approval process for code-compliant residential PV systems. Based on national model building, electrical, and fire codes, the SolarAPP+ automatically performs a compliance check of the inputs supplied by the solar contractor to ensure the proposed PV system meets code requirements. The system then produces an inspection checklist for use in verifying installation practices, workmanship, and adherence to the approved design.

To test and confirm SolarAPP + functionality and related impacts, NREL conducted a two-phase pilot with five participating AHJs and 16 solar contractors, spanning from November 2020 through December 2021. The pilot was set up to evaluate the ability of SolarAPP+ to deliver instant permits and assess its impact on four critical areas within each AHJ:

- AHJ time saved

- Permit review timelines

- Inspection results

- Solar adoption timelines.

The pilot evaluated 84 traditionally permitted projects and 208 projects submitted through SolarAPP + across the five AHJs. The pilot confirmed that SolarAPP + reduced permit review times to less than one day, reduced adoption timelines by an average of 12 days, saved an estimated 236 staff hours (and an additional 2,509 staff hours outside of the pilot), and had comparable inspection results to those found in traditional permitting. The pilot identified key lessons for improving SolarAPP + , including ways to streamline SolarAPP + adoption, development of training resources, and expansion of supported products. This report details these pilot results along with solar permitting context. 


\section{Traditional Permit Processing Meets the SolarAPP+}

Most residential rooftop PV installations require a combination of permitting, inspection, and interconnection approvals from the local AHJ and utility. This process helps ensure that residential PV systems meet design, safety, and other requirements set forth by state and local authorities (Stanfield et al. 2013).

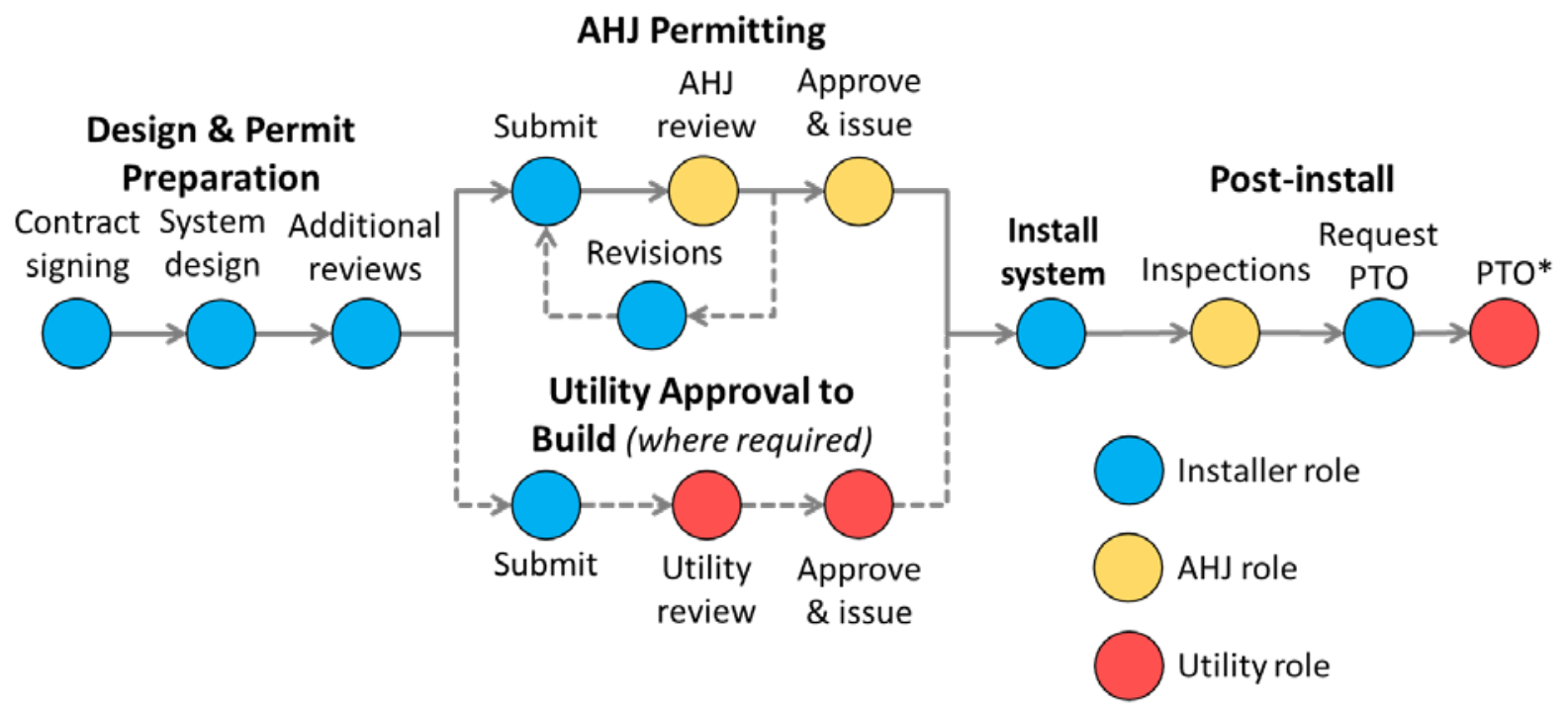

Figure 1. The residential PV permitting process

*Permission to Operate (PTO).

The typical AHJ permitting process for residential PV systems is as follows (Figure 1):

1. Design and Permit Preparation. Once a customer signs the contract, the installer completes the final system design. If required by the AHJ, professional engineering and other reviews are also performed.

2. Permit Submission. The installer then completes the AHJ permit application(s), which may include building/site information, electrical diagrams, supporting calculations, and equipment lists. Applications submission methods vary by AHJ and may include inperson drop-off, over-the-counter same day review, mail-in, e-mail, and/or an online permit portal.

3. AHJ Reviews. The AHJ checks the application for completeness. Then, one or more departments may review the proposed system for compliance with design, safety, zoning, and/or other code-related requirements.

4. Approval and Issuance. If these requirements are met and the required fees paid, the AHJ issues the permit.

5. Installation. Once all approvals are received (including utility interconnection where required), system installation is scheduled and commences. 
6. Inspections. The AHJ, and in some cases the utility, may conduct one or more inspections during or after installation to ensure the installed PV system aligns with the approved design.

7. Permission to Operate. Final inspection results and other paperwork is sent to the utility for final permission to operate. If approved, the system is commissioned.

It is not uncommon for a contractor to submit one or more permit revisions to the AHJ (Stanfield et al. 2012). This can occur either at the AHJ's request, if the project was deemed not codecompliant, or at the homeowner or contractor's request, if the system design changed (e.g., to increase or reduce system capacity, or due to changes in equipment availability). These revisions may then require the applicant and AHJ to start at the beginning of the review process, resulting in potential delays and additional costs (Figure 1).

\subsection{Impacts of Permitting Review and Requirement Variation}

While the permitting process is important for ensuring safe, reliable, and code-compliant PV system installations, its implementation often creates challenges for efficient, low-cost PV deployment. These challenges are often associated with permitting review requirements and approval delays that can influence adoption timelines and install costs (Cook et al. 2021a; O'Shaughnessy et al. 2022). The variability in permitting processes across jurisdictions also creates hurdles, and slower or more onerous processes may further exacerbate timeline and cost impacts for projects in those jurisdictions (Burkhardt et al. 2015; Cook et al. 2021a; Dong and Wiser 2013; O'Shaughnessy et al. 2022). These permitting issues, paired with inspection and interconnection related delays and requirements, may lead to lower PV adoption rates, directly through higher costs, design modifications impacting project economics, contract cancellations, etc., and indirectly through negative customer experience resulting in fewer word-of-mouth and network effects (Cook et al. 2021a; O'Shaughnessy et al. 2020; Sinitskaya et al. 2019; Wolske et al. 2020).

Though national building, electric, and fire codes exist, and versions of these codes are widely adopted nationwide, there is significant variation across AHJs in which relevant model code is adopted and how it is interpreted and subsequently enforced. This variability is in part a function of the decentralized nature of permitting in the United States (Seel et al. 2014). Some states set mandatory code version requirements while others do not, and AHJs may or may not be able to adopt more stringent codes where state base codes apply (Stanfield et al. 2012). A recent survey suggests that installers struggle to navigate the differing requirements between each of the AHJs they serve and in some cases charge higher prices to customers to cover the costs of burdensome AHJ requirements, or even avoid some AHJs altogether (Cook et al. 2021a).

Soft costs refer to the non-hardware costs of PV systems and generally include permitting, inspection, interconnection, installation labor, and customer acquisition. These costs may be passed on to consumers in the form of higher prices (Cook et al. 2021a). The soft cost impacts associated with permitting are well-documented (Feldman et al. 2021; O'Shaughnessy et al. 2019). Feldman et al. (2021) used NREL's cost modeling approach to benchmark average U.S. residential rooftop PV soft costs (non-hardware costs) and found an average cost of $\$ 1.5 /$ watt $(\mathrm{W})$, or approximately $\$ 10,300$ for an average 7-kilowatt $(\mathrm{kW})$ system. Of these total soft costs, AHJ permit and inspection costs are estimated at $\$ 0.17 / \mathrm{W}$ or $\$ 1,260$. Higher cost jurisdictions may have much higher permitting costs than these averages (Burkhardt et al. 2015). For 
example, Dong and Wiser (2013) estimated permitting cost impacts of $\$ 0.27-\$ 0.77 / \mathrm{W}$. More recently, one-third of surveyed installers reported charging $10 \%-20 \%$ premiums $(\$ 0.4-\$ 0.7 / \mathrm{W})$ or more for installs in AHJs with burdensome permitting requirements (Cook et al. 2021a).

As with permitting requirements, timelines for permit approval also vary widely. A recent study of over 200,000 projects installed nationwide found a median permit submission to approval timeline of seven days (Cook et al. 2021b; NREL 2021). However, this median belies significant variability between approval timelines in some AHJs and for some projects, and longer timelines can range up to three weeks (at the $75^{\text {th }}$ percentile) to a month or more. When surveyed by Cook et al. (2021a), AHJ permitting has been cited as the primary source of project delays and cancellations for mid-to-large installers and small installers, respectively. However, permitting delays are not solely attributable to AHJs. Several studies have found noticeable timeline differences between individual installers at the same AHJ, and AHJs report difficulties with some installers submitting incorrect or incomplete applications and/or system designs (O’Shaughnessy et al. 2020; Stanfield et al. 2013, 2012).

\subsection{Instant Permitting Software and SolarAPP+ Development}

Despite these challenges, improved and more efficient permitting processes, especially instant permit portals similar to the SolarAPP+, are likely associated with higher PV deployment rates in those AHJs that have had the resources to develop them in-house (Hsu 2018; Parsons and Josefowitz 2021; White 2019). Absent a scalable model available to all AHJs, certain AHJs have developed their own instant permitting software systems, such as Los Angeles, California; San Jose, California; Alameda, California; and Fairfield, Connecticut (Parsons and Josefowitz 2021). NREL and solar stakeholders identified the need for a consistent, nationwide automated solar permitting platform to minimize the time and labor investment required for AHJs to develop novel permitting systems.

The SolarAPP+ design was informed by the instant permitting processes developed by other communities, with the intent to be available to AHJs at no cost. This product was developed through a collaborative partnership between NREL, industry, and the building safety community, with funding from the U.S. Department of Energy (DOE). ${ }^{1}$ The project began in September 2019 and was implemented in three steps. First, NREL developed and tested the software with the solar industry and building safety community for alignment with underlying national model codes. ${ }^{2}$ Second, NREL piloted the software with five communities, and those results are summarized here. Third, the SolarAPP + software launch was publicly announced by DOE Secretary Jennifer Granholm in July 2021, while NREL continues to deploy the software with interested AHJs.

The SolarAPP+ was designed to streamline the permitting process for typical residential rooftop solar PV installations that meet certain eligibility requirements. ${ }^{3}$ As of September 2021, the

\footnotetext{
${ }^{1}$ For more information on the SolarAPP+ and a list of all the partners involved in the project, see https://solarapp.nrel.gov/.

2017 National Electric Code (NEC), 2018 International Building Code (IBC), and 2018 International Residential Code (IRC) among others.

${ }^{3}$ For full listing of the SolarAPP+ eligibility requirements for residential solar PV systems, see https://help.solarapp.org/article/43-what-types-of-systems-are-not-eligible-for-solarapp-review.
} 
major SolarAPP + support parameters include new rooftop residential PV systems on existing homes where the PV system weighs less than 4 pounds per square foot, and the home is served by equal to or less than 400 Amp main service and 225 Amp busbars, with no existing power generation equipment already on-site (i.e., existing PV or battery storage systems). ${ }^{4}$

For eligible systems, the SolarAPP+ automates the review of standardized residential solar permit applications through the following steps:

- Solar contractor submits an application with design specifications through the SolarAPP+.

- The SolarAPP+ checks the application to ensure the system design is code compliant.

- Code-compliant applications are issued a permit instantly after fee payment.

Permit applications that are not code-compliant are instantly rejected, providing the solar contractor with immediate feedback on the need for corrections prior to fee payment. Additionally, the SolarAPP+ produces an inspection checklist replicating the application details for inspectors to utilize during the inspection process to confirm the system as installed matches the design approved within the SolarAPP+.

${ }^{4}$ As of this publication, the development team is working to expand eligibility across PV system types and other features such as storage. For the full SolarAPP+ product road map see: https://help.solar-app.org/article/177solarapp-product-roadmap. 


\section{SolarAPP+ Pilot}

NREL conducted a pilot of the software to provide AHJs, solar contractors, and the broader solar industry with information on the performance of the SolarAPP+, as used by AHJs with diverse characteristics and needs. The pilot provided qualitative and quantitative evidence of the benefits, trade-offs, and overall performance of the SolarAPP+, including achievement of the project goals to:

1. Reduce permit application review timelines

2. Reduce solar adoption timelines

3. Save AHJs time and resources associated with permit review and approval

4. Maintain or improve contractor inspection pass rates.

\subsection{Pilot Participants}

NREL recruited five AHJs to participate in Phases 1 and 2 of the SolarAPP+ pilot. Phase 1 consisted of three AHJs and began in late 2020. Phase 2 consisted of two AHJs and began in spring 2021. Separation of the pilot into two phases allowed the SolarAPP+ team to make improvements in SolarAPP+ functionality and implementation process based on Phase 1 results and stakeholder feedback, which were then tested in Phase 2. Participating AHJs were eligible for the pilot based on code year ${ }^{5}$ and reflected a diversity of characteristics such as solar volume, permitting software, government type, size, geography, and interest in streamlining the solar permitting process, as summarized in Table 1. AHJs were selected for each phase of the pilot based on their readiness to adopt the SolarAPP+. This phased approach also allowed the opportunity for adopting changes in the latter phase based on the lessons learned from implementation of the first phase.

Table 1. SolarAPP+ Pilot AHJ Characteristics by Phase and SolarAPP+ Adoption Pathway

\begin{tabular}{|c|c|c|c|c|c|c|c|c|c|}
\hline AHJ & State & $\begin{array}{l}\text { Pilot } \\
\text { Phase }\end{array}$ & $\begin{array}{c}\text { SolarAPP+ } \\
\text { Adoption } \\
\text { Pathway }\end{array}$ & Pop. & $\begin{array}{c}2020 \\
\text { Permit } \\
\text { Volume }\end{array}$ & $\begin{array}{l}\text { Existing } \\
\text { Permit } \\
\text { Software }\end{array}$ & $\begin{array}{l}\text { Permit } \\
\text { Fee }\end{array}$ & 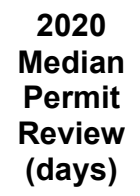 & $\begin{array}{c}2020 \\
\text { Median } \\
\text { Time to } \\
\text { Inspection } \\
\text { (days) }\end{array}$ \\
\hline $\begin{array}{l}\text { Pima } \\
\text { County }\end{array}$ & $A Z$ & 1 & A & $500,804^{*}$ & 1,682 & $\begin{array}{c}\text { Accela } \\
\text { (ACA) }\end{array}$ & $\$ 94$ & 8 & 34 \\
\hline $\begin{array}{l}\text { Pleasant } \\
\text { Hill }\end{array}$ & $\mathrm{CA}$ & 1 & B & 33,152 & 180 & Accela & $\$ 235$ & 1 & 36 \\
\hline Tucson & $A Z$ & 1 & $A$ & 542,629 & 1,534 & EnerGov & $\$ 99$ & 12 & 40 \\
\hline Menifee & $\mathrm{CA}$ & 2 & $A$ & 102,527 & 691 & $\begin{array}{l}\text { Accela } \\
\text { (ACA) }\end{array}$ & $\$ 220$ & 9 & 75 \\
\hline Stockton & $\mathrm{CA}$ & 2 & $A$ & 320,804 & 2,410 & $\begin{array}{c}\text { Accela } \\
\text { (ACA) }\end{array}$ & $\$ 300$ & 1 & 34 \\
\hline
\end{tabular}

${ }^{*}$ Pima County population excluding Tucson.

${ }^{5}$ The SolarAPP+ is based on the 2017 NEC, 2018 IBC, and 2018 IRC, so participating AHJs were required to have adopted these codes. 
Each AHJ chose one of two adoption pathways to implement the SolarAPP + with their permitting process, as shown in Figure $2 .{ }^{6}$ Adoption Pathway A is a software-integrated approach, requiring the development of an instant permitting process within the AHJ's existing permitting software that interfaces with the SolarAPP+. Adoption Pathway B is a stand-alone approach and the SolarAPP+ issues the permits.

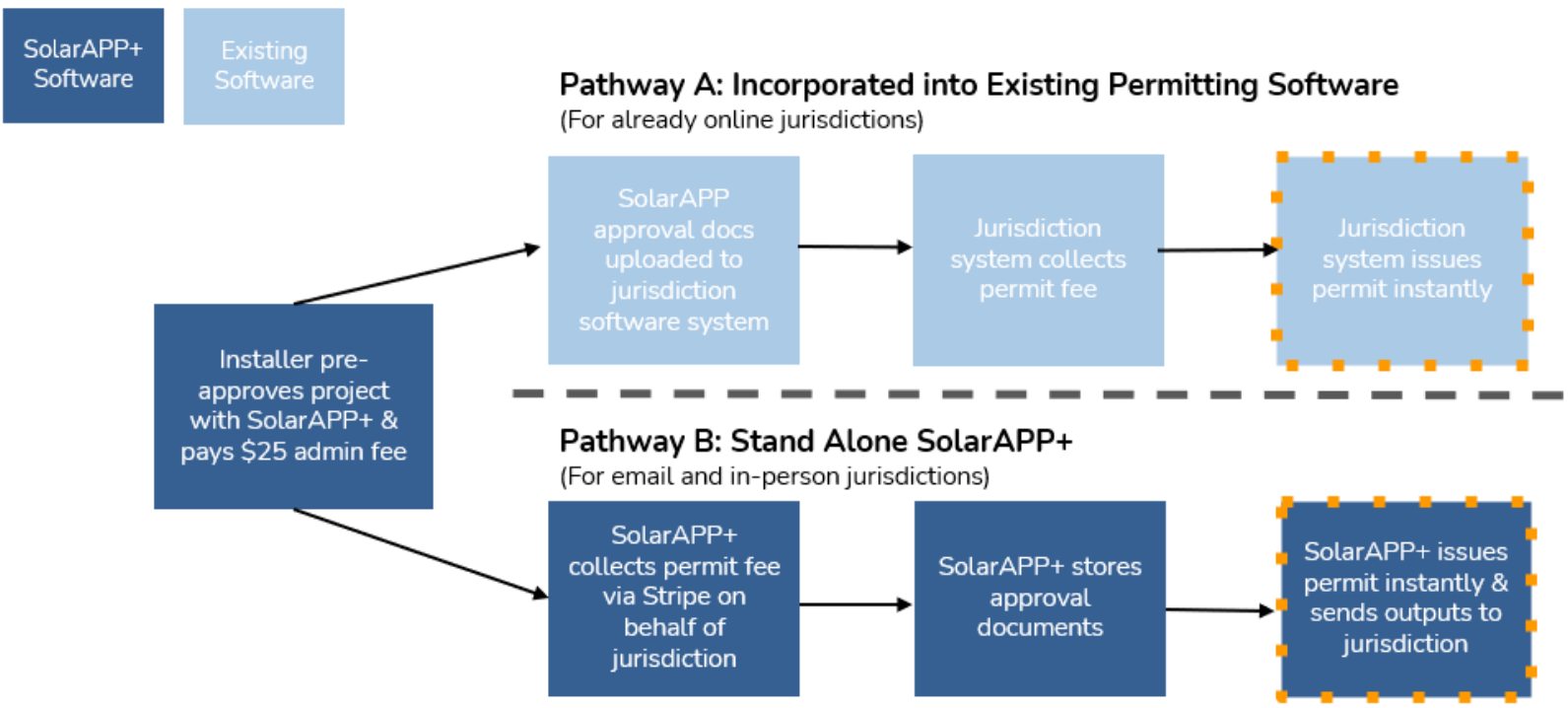

Figure 2. SolarAPP+ adoption pathways

Once the adoption pathway was in place, NREL worked with each AHJ to invite solar contractors to participate in the pilot. SolarAPP+ development partners active in each AHJ were invited to participate, along with high-volume local installers, nominated by the AHJ, who were previously unfamiliar with the SolarAPP + . The participating contractors in each AHJ are listed in Table 2.

Table 2. SolarAPP+ Pilot Contractors by AHJ

\begin{tabular}{|c|c|}
\hline AHJ & Participating Contractors \\
\hline Menifee, CA & $\begin{array}{l}\text { Energy Service Partners, Freedom Forever, New Day Solar, SolarMax, Solcius, } \\
\text { SunPower, Sunrun, Tesla }\end{array}$ \\
\hline Pima County, AZ & $\begin{array}{l}\text { Custom Solar \& Leisure, Net Zero Solar, Solar Solution AZ, Sunbright Solar, } \\
\text { Technicians for Sustainability, Tesla, The Solar Store, Titan Solar Power }\end{array}$ \\
\hline Pleasant Hill, CA & Freedom Forever, Sunrun, Tesla \\
\hline Stockton, CA & $\begin{array}{l}\text { Energy Service Partners, Freedom Forever, Solar Works, SunPower, Sunrun, } \\
\text { Tesla }\end{array}$ \\
\hline Tucson, AZ & $\begin{array}{l}\text { Custom Solar \& Leisure, Net Zero Solar, Solar Solution AZ, Technicians for } \\
\text { Sustainability, Tesla, The Solar Store, Titan Solar Power }\end{array}$ \\
\hline
\end{tabular}

\footnotetext{
${ }^{6}$ The SolarAPP+ adoption pathways are discussed in more detail in Section 5.1.
} 


\subsection{Pilot Structure}

The pilot was structured as a control trial to provide a direct comparison of the traditional permit review process and the SolarAPP+ process for each AHJ. For the duration of the pilot, participating contractors divided SolarAPP+ eligible projects into two groups:

- The control group of projects consisted of projects eligible to be permitted through the SolarAPP+ but permitted through the AHJ's traditional process (referred to as "control projects").

- The treatment group of projects consisted of projects that were eligible for and permitted through the SolarAPP+ (referred to as "SolarAPP+ projects").

The duration of the pilot as implemented by each AHJ was marked by the following milestones:

1. Pilot Launch-Control and SolarAPP+ Permit Submission: Contractors were asked to submit eligible projects alternately through the traditional process and through the SolarAPP+ until a minimum of 10 projects in the control group were permitted through the SolarAPP+ and an equal number of control projects were permitted through the AHJ's traditional process.

SolarAPP + Permit Submission Only: Once the minimum of 10 control permit submissions was met, pilot contractors submitted all additional eligible projects through the SolarAPP+.

2. Pilot Closure to New Permits: Once NREL, the AHJ, and participating contractors deemed that a sufficient number of SolarAPP+ projects had been submitted, ${ }^{7}$ the pilot was closed to new projects and pilot participants continued to provide data on the progress of control and SolarAPP+ pilot projects through AHJ inspection.

3. End of Data Collection on Inspections: The End of Data Collection on Inspections date marked the end of contractor and AHJ data collection for the control and treatment projects. This date was established to allow sufficient time for at least half the pilot projects submitted through SolarAPP+ in each AHJ to pass inspection. ${ }^{8}$

\footnotetext{
${ }^{7}$ The determination of what constituted a "sufficient number of SolarAPP + projects" for each AHJ was influenced by the number of SolarAPP+ projects submitted by each contractor, the number of projects submitted through SolarAPP+ that were subsequently canceled, the successful resolution of implementation challenges, the duration of the pilot, and other factors.

${ }^{8}$ Pilot projects not yet inspected by the End of Data Collection on Inspections date were included in permit data analysis and excluded from inspection data analysis.
} 
Each AHJ conducted the pilot on similar but not identical timelines, as shown in Table $3 .^{9}$

Table 3. Pilot Milestones, in Chronological Order of Launch

\begin{tabular}{llrrc}
\hline AHJ & $\begin{array}{l}\text { Pilot } \\
\text { Phase }\end{array}$ & Pilot Launch & $\begin{array}{l}\text { Pilot Closure to } \\
\text { New Permits }\end{array}$ & $\begin{array}{l}\text { End of Data } \\
\text { Collection on } \\
\text { Inspections }\end{array}$ \\
\hline Pleasant Hill & 1 & $11 / 3 / 20$ & $5 / 14 / 21$ & $7 / 2 / 21$ \\
\hline Pima County/Tucsona & 1 & $12 / 16 / 20$ & $5 / 4 / 21$ & $6 / 29 / 21$ \\
Menifee & 2 & $5 / 4 / 21$ & $7 / 14 / 21$ & $10 / 18 / 21$ \\
Stockton & 2 & $7 / 1 / 21$ & $10 / 7 / 21$ & $12 / 3 / 21$ \\
\hline
\end{tabular}

a Pima County and Tucson conducted the SolarAPP+ pilot jointly, though pilot results are reported separately.

NREL collected data from each participating AHJ and contractor for control and SolarAPP+ projects regarding permit characteristics and the time and resources required for the various steps in the review and inspection processes. ${ }^{10}$ From Pilot Launch to End of Data Collection on Inspections, NREL met regularly with the participating AHJ and contractors to address implementation challenges and solicit feedback for improving SolarAPP + functionality and implementation.

\section{Limitations of the Pilot}

A major limitation of the structure of the pilot was the decision to set the minimum control group size to 10 projects per AHJ. Although a control group this small is not statistically significant, this threshold was selected to balance data collection with AHJs' desire to fully implement SolarAPP+ to alleviate staffing constraints and permit review timelines as quickly as possible. To mitigate the impact of the control group size, the project team collected certain historical baseline data from each AHJ regarding residential solar permit applications and inspections over the prior 3-5 years. The AHJ historical baseline data were used to identify median permit review times, median project time from permit submission to passed inspection, and inspection failure rates. For these metrics, historical, control group, and treatment group data are reported.

Though the AHJ historical data were useful, they had limitations. First, the AHJ solar permit review processes were inconsistent across the historical period. Changes to the solar permit review processes enacted by AHJs in the historical period included implementation of electronic permit submission, changes to documentation requires, and process adjustments to reflect staffing levels. Second, the AHJs were collectively unable to provide detailed historical data on instances of permit revision review, duration of inspections, and causes of inspection failures. For these metrics, control group and treatment group data were collected and analyzed. The project team used the available historical data to provide context for interpreting the pilot results.

\footnotetext{
${ }^{9}$ Pilot timelines varied based on permit volume, proportion of projects with completed inspections, and AHJ readiness to launch the SolarAPP+ to all contractors.

${ }^{10}$ Appendix A lists data types collected from pilot AHJs and contractors. The SolarAPP+ pilot Phase 1 and Phase 2 data will be published online.
} 
Though the control group was required to have a minimum of 10 projects in each AHJ, some of the participating AHJs had significantly larger control groups. In part, the discrepancy resulted from differences in AHJ permit volume and the availability of eligible control group projects. The project team aimed to have each participating contractor enroll at least two control group and two treatment group projects in the pilot to allow for multiple data points for each contractor. Control groups for AHJs with more participating contractors were substantially larger than the 10-project minimum. As a result, the data were more robust for the AHJs with larger control groups.

Another limitation of the control trial data is the variation in the process for treatment group projects across the pilot period. The pilot was conducted in two phases to allow for platform improvements identified or made during Phase 1 to be tested in Phase 2. During Phase 1, significant improvements were made to SolarAPP+ based on AHJ and contractor user feedback. Some of these improvements, such as expanding eligible roof coverings, were prompted by use cases the SolarAPP + development team had not previously considered. Most of these improvements were implemented during Phase 1, so the Phase 1 AHJs extended the pilot enrollment period for SolarAPP + projects to test successful implementation of the improvements. The user testing resulted in an overall improved SolarAPP+ platform, but an implication of this approach was that the Phase 2 treatment group projects were not subject to exactly the same treatment as Phase 1.

Finally, the quality of the pilot results depended on the quality of the data collected from AHJs and contractors. Though the project team met with pilot participants regularly to encourage complete and accurate data entry, some pilot participants provided incomplete data, misinterpreted data entry fields, or failed to update the data to reflect project updates. Summary tables and charts exclude missing data related to AHJ permit and revision savings, inspection durations, and causes of inspection failure. 


\section{Pilot Results}

This section presents the results of the SolarAPP+ pilot Phases 1 and 2. As discussed earlier, separation of the pilot into two phases allowed the SolarAPP+ team to make improvements in SolarAPP + functionality and implementation process based on Phase 1 results and stakeholder feedback, which were then tested in Phase 2. Notably, the SolarAPP+ adoption pathways were streamlined, and additional contractor education resources were developed between Phases 1 and 2. However, the structures of Phases 1 and 2 were similar enough that the results of both phases are presented together.

\subsection{AHJ Permit Volume}

All five pilot communities provided historical permit and inspection data that was crossreferenced with data collected during the pilot. The residential permit volume historical data, shown in Table 4, illustrates that interest in the SolarAPP+ is present across jurisdictions with widely differing solar activity. Year-to-year AHJ solar permit application volumes fluctuated, but aside from identifying the pandemic as a factor affecting the volume of solar permit applications in 2020, the AHJs were not able to identify other causes of this fluctuation.

Table 4. AHJ Historical Residential Permit Submissions

\begin{tabular}{lcrrrrrr}
\hline AHJ & $\begin{array}{c}\text { Pilot } \\
\text { Phase }\end{array}$ & $\mathbf{2 0 1 6}$ & $\mathbf{2 0 1 7}$ & $\mathbf{2 0 1 8}$ & $\mathbf{2 0 1 9}$ & $\mathbf{2 0 2 0}$ & $\begin{array}{r}\text { Total } \\
(\mathbf{2 0 1 6 - 2 0 2 0 )}\end{array}$ \\
\hline Pima County & 1 & 1,801 & 1,633 & 1,740 & 1,285 & 1,682 & 8,264 \\
\hline Pleasant Hill & 1 & 220 & 195 & 197 & 286 & 180 & 1,078 \\
Tucson & 1 & 1,883 & 1,627 & 1,812 & 1,285 & 1,534 & 8,141 \\
Menifee & 2 & 819 & 1,099 & 1,115 & 1,053 & 691 & 4,777 \\
Stockton & 2 & No Data & No Data & No Data & 2,079 & 2,410 & 4,489 \\
\hline
\end{tabular}

The volume of projects tracked by each AHJ through the pilot is shown in Table 5. Despite the months-long duration of each pilot, not all projects completed the final inspection prior to the End of Data Collection on Inspections date. Further discussion of inspection completions and the relevant pass rates for the control and SolarAPP+ groups are discussed in Section 4.3.

Table 5. Residential Solar Permit Submittals and Passed Inspections During Pilot

\begin{tabular}{l|cc|cc}
\hline AHJ & \multicolumn{2}{|c|}{ Control } & \multicolumn{2}{c}{ SolarAPP+ } \\
& Submitted & $\begin{array}{c}\text { Passed } \\
\text { Inspection }\end{array}$ & Submitted & $\begin{array}{c}\text { Passed } \\
\text { Inspection }\end{array}$ \\
\hline Menifee & 20 & 15 & 26 & 18 \\
\hline Pima County & 24 & 18 & 55 & 34 \\
\hline Pleasant Hill & 10 & 5 & 18 & 10 \\
Stockton & 14 & 11 & 48 & 32 \\
\hline Tucson & 16 & 12 & 73 & 44 \\
\hline Total & $\mathbf{8 4}$ & $\mathbf{5 8}$ & $\mathbf{2 2 0}$ & $\mathbf{1 3 8}$ \\
\hline
\end{tabular}




\subsection{AHJ Permit Review Impacts}

As an automated permitting tool, the SolarAPP+ was expected to have the most significant impact on AHJ permit review time. The average traditional permit review times ranged from 18 days for Tucson to less than a day for Pleasant Hill, meaning that on average Pleasant Hill was able to review permits the same day they were received. By providing instantaneous review, the SolarAPP + reduced the average permit review time to zero days, or in other words, same-day approval, as shown in Figure 3.

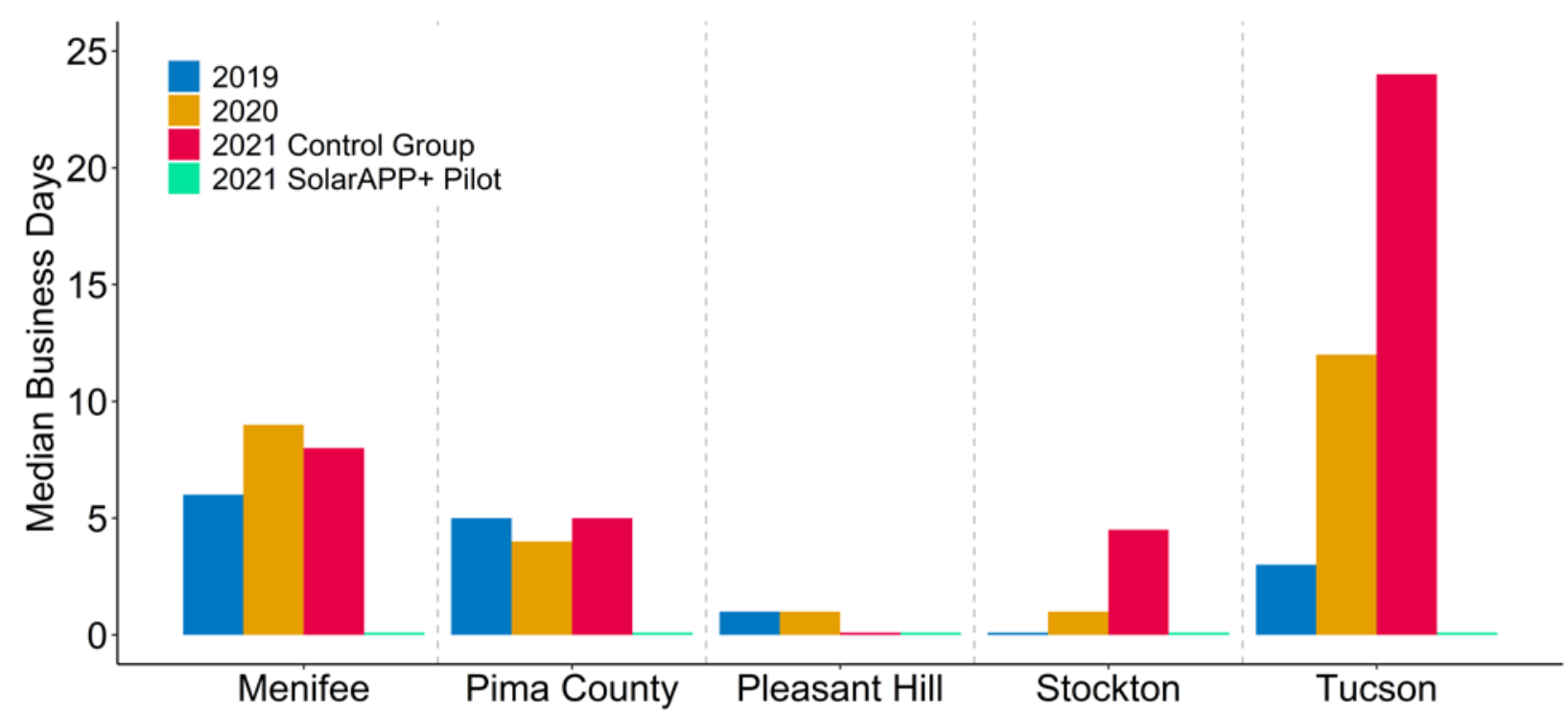

Figure 3. Median residential solar permit review time (business days)

Menifee 2017-2020 permit review time estimated from SolarTrace (NREL 2021). ${ }^{11}$

The impact of the SolarAPP+ on permit review times was most notable for Tucson, followed by Menifee. Although the impact on permit review time for Pleasant Hill was smallest, Pleasant Hill expressed that the time savings for permit review staff and adopting homeowners was still valuable, as discussed in Section 4.5 and 4.6.

In addition to the initial permit review, AHJs also review any permit revisions submitted by contractors. Although data on historical permit revision rates and review was unavailable, pilot participants tracked the frequency, causes, and review time for permit revisions for both control and SolarAPP+ projects in the pilot. The proportion of control projects with revisions was $8 \%$, while the proportion of SolarAPP+ projects with revisions was approximately $37 \%$. There are two major factors that relate to the higher occurrence of permit revisions for SolarAPP+ projects. First, contractors experienced a learning period with the SolarAPP + in understanding the intent of the input questions. ${ }^{12}$ Second, the software originally altered the "status" of a SolarAPP+ project if the contractor accidently or purposefully hit the Edit Application button. As a result, contractors mistakenly assumed it was necessary for them to resubmit the project to return to

\footnotetext{
${ }^{11}$ Available at https://solarapp.nrel.gov/solarTRACE.

${ }^{12}$ On average, the total contractor time spent on residential solar permits slightly increased from 1.94 hours for control submittals to 2.05 hours for SolarAPP+ projects.
} 
"approved" status, which led to a higher number of revised application submittals in Phase 1. This issue has since been resolved. Figure 4 shows the frequency of SolarAPP+ permit revisions.

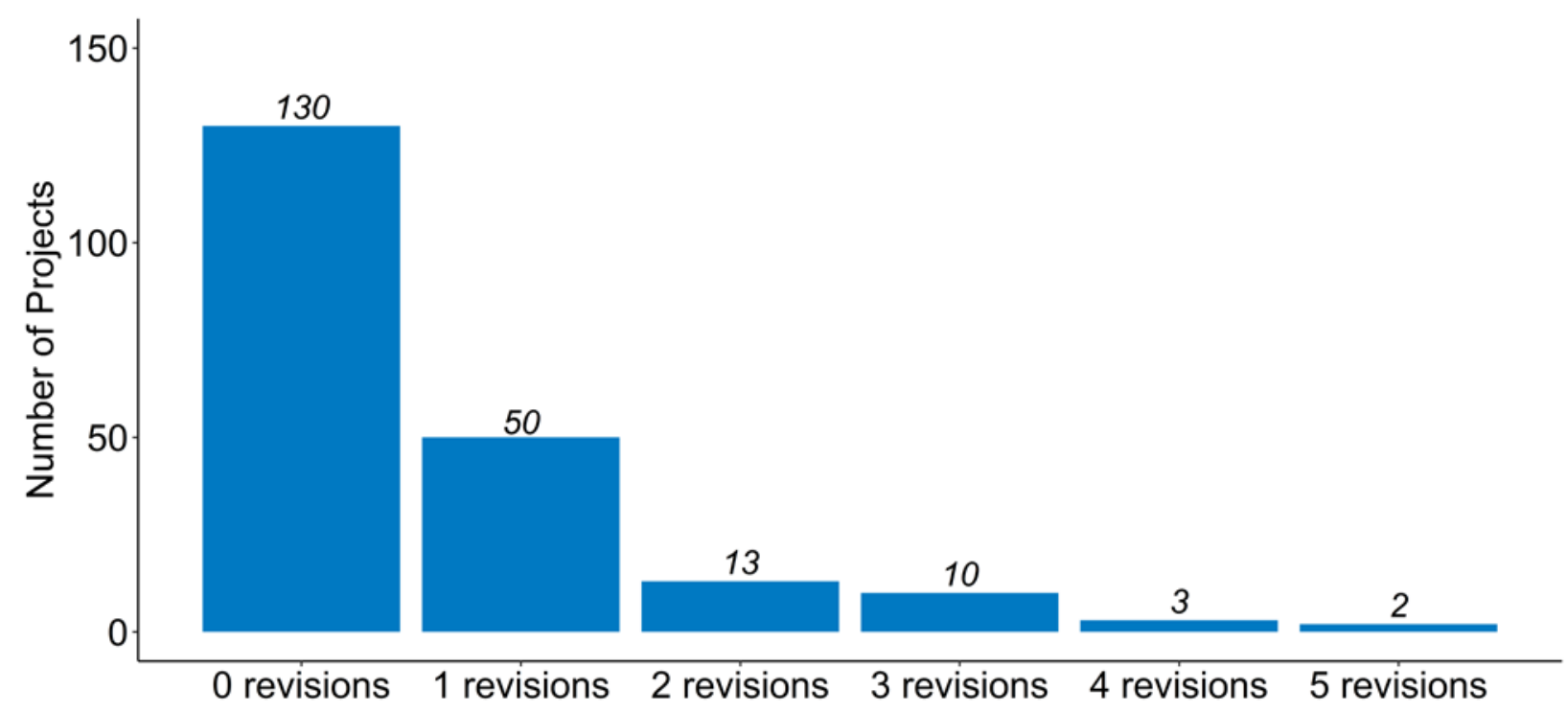

Figure 4. Frequency of permit revisions among SolarAPP+ projects across all AHJs

Pilot contractors were asked to track the causes for permit revisions, but this tracking was not always consistent. Approximately half of the stated causes of revisions were associated with system design changes that would have also required a permit revision via the traditional pathway, such as changes to equipment, permit size, or main panel upgrades. The remaining revision causes reflect contractor input changes, which are expected to reduce in frequency as contractors become familiar with the software.

Importantly, revisions submitted through the SolarAPP+ are instantly reviewed and approved if code-compliant, thereby not resulting in significant impacts on contractors. Depending on the selected SolarAPP+ adoption pathway, some AHJs need to append the new revised documents to existing permit files, while for others this process is automated by the AHJ's permitting software. Where automated, the revision process does not affect AHJs. In contrast, manual revision entry can require several minutes per project for AHJ staff to update permit records with the new documents. The incidence of revisions is expected to decline as contractors get more comfortable with the application and the training resources available in the SolarAPP + knowledge base ${ }^{13}$ and improvements to the software are released to reduce contractor misunderstanding. The SolarAPP + team is also working with software vendors to further automate the AHJ revision process.

${ }^{13}$ The SolarAPP+ Knowledge Base is available at: https:/help.solar-app.org/. 


\subsection{AHJ Inspection Pass Rates}

In addition to permit review impacts, the pilot sought to identify the extent of the impacts of the SolarAPP + on inspection pass rates. Historical inspection failure data from 2020 was compared to inspection failures from the pilot. Table 6 shows the number of failed inspections and the inspection failure rate for each AHJ. ${ }^{14}$

Table 6. Historical and Pilot Inspection Failure Rates by AHJ

\begin{tabular}{lccccc}
\hline AHJ & $\begin{array}{c}\text { Historical } \\
\text { Failure Rate } \\
(\mathbf{2 0 2 0 )}\end{array}$ & $\begin{array}{c}\text { Control } \\
\text { Failures I } \\
\text { Inspections }\end{array}$ & $\begin{array}{c}\text { Control } \\
\text { Failure Rate }\end{array}$ & $\begin{array}{c}\text { SolarAPP+ } \\
\text { Failures } / \\
\text { Inspections }\end{array}$ & $\begin{array}{c}\text { SolarAPP+ } \\
\text { Failure Rate }\end{array}$ \\
\hline Menifee & $16 \%$ & $3 / 18$ & $17 \%$ & $5 / 26$ & $19 \%$ \\
\hline Pima County & $17 \%$ & $0 / 18$ & $0 \%$ & $4 / 34$ & $12 \%$ \\
\hline Pleasant Hill & $19 \%$ & $0 / 5$ & $0 \%$ & $0 / 10$ & $0 \%$ \\
\hline Stockton^ & $32 \%$ & $5 / 13$ & $38 \%$ & $21 / 53$ & $40 \%$ \\
\hline Tucson & $4 \%$ & $0 / 12$ & $0 \%$ & $2 / 44$ & $5 \%$ \\
\hline Total & N/A & $\mathbf{8 / 6 6}$ & $\mathbf{1 2 \%}$ & $\mathbf{3 2 / 1 6 7}$ & $\mathbf{1 9 \%}$ \\
\hline
\end{tabular}

^Stockton historical and pilot data include inspection failures due to canceled or rescheduled inspections.

A total of 167 SolarAPP+ inspections were completed during the pilot, of which there were 32 failures, resulting in an overall SolarAPP+ inspection failure rate of $19 \%$ for the pilot, as compared to $12 \%$ for the control projects. Relative to the historical inspection failure rate by AHJ, SolarAPP+ inspection failure rates are comparable. These results should be considered illustrative rather than representative, due to small sample sizes. To understand whether inspection failures were a result of the SolarAPP + , pilot contractors tracked the causes for the inspection failures, shown in Figure 5.

\footnotetext{
${ }^{14}$ Due to variation in historical inspection data availability, the historical inspection failure rate could be calculated based on the number of failed inspections out of total failed inspections but not for the number of projects with inspection failures out of the total number of projects.
} 


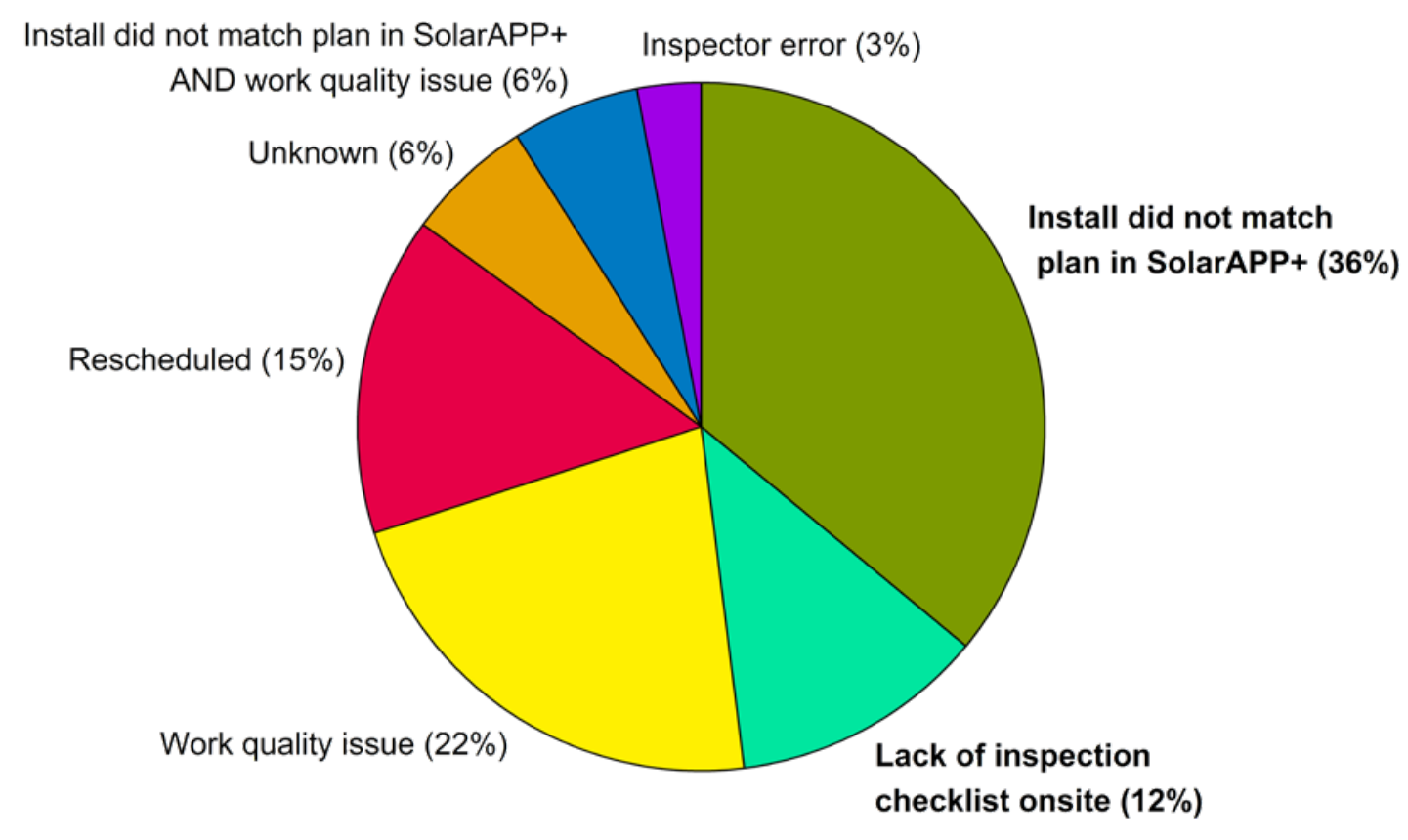

Figure 5. Reported causes of SolarAPP+ inspection failures, with avoidable failures in bold

The most common reason for inspection failure was that the project installation did not match the plan in SolarAPP+. In short, the project was installed differently from the design input into the application. Within this group, a relatively common error involved the contractor installing a different inverter model number than that listed in SolarAPP+. These failures could have occurred whether the SolarAPP+ or a traditional plan set was used, given the contractor may not have updated their traditional plan submission with the same information. Even so, this could have been avoided by the contractor submitting a revised SolarAPP+ permit with the correct installed equipment before scheduling the inspection. The other cause of inspection failures directly related to SolarAPP + was due to contractors' lack of required inspection materials onsite, including SolarAPP+ documentation.

These two avoidable failure categories composed roughly half of all the failed inspections during the pilot. With further contractor education and familiarity with SolarAPP+, it is possible that the application may reduce inspection failures by a comparable percentage overall. That is because the contractor can use the SolarAPP+ inspection checklist as a final quality check prior to inspection and then ensure an accurate checklist is available on-site at the time of inspection.

SolarAPP + was not a factor in the remaining failure causes: work quality, inspection rescheduling, and one error by the inspector that was resolved and passed after further investigation. Thus, SolarAPP+ will not be able to reduce all instances of inspection failures in the future.

\subsection{AHJ Inspection Durations}

The pilot also tracked the impact of the SolarAPP+ on the duration of inspections and aimed to identify any potential impacts associated with inspectors' use of the simple, standardized 
inspection checklist generated by SolarAPP + for each project. This checklist includes all the critical elements that must be verified during inspection. The checklist is further accompanied by the SolarAPP+ approval document, which captures all inputs and calculations that were used to generate the checklist. The checklist and supporting documentation can then be used to verify installation practices, workmanship, and adherence to the approved design.

In summary, inspector use of the SolarAPP+ checklist did not appear to significantly impact inspection durations across all five AHJs, as shown in Figure 6. Pima County experienced a slight decrease in inspection duration of just over two minutes, while Pleasant Hill, Stockton, and Tucson each experienced a modest increase in inspection duration of one to two minutes. Menifee saw no change to inspection duration. Over the course of the pilot, AHJs saw improvement in the inspection durations, suggesting time increases associated with the SolarAPP + can be mitigated as inspectors and contractors became more familiar with the process.

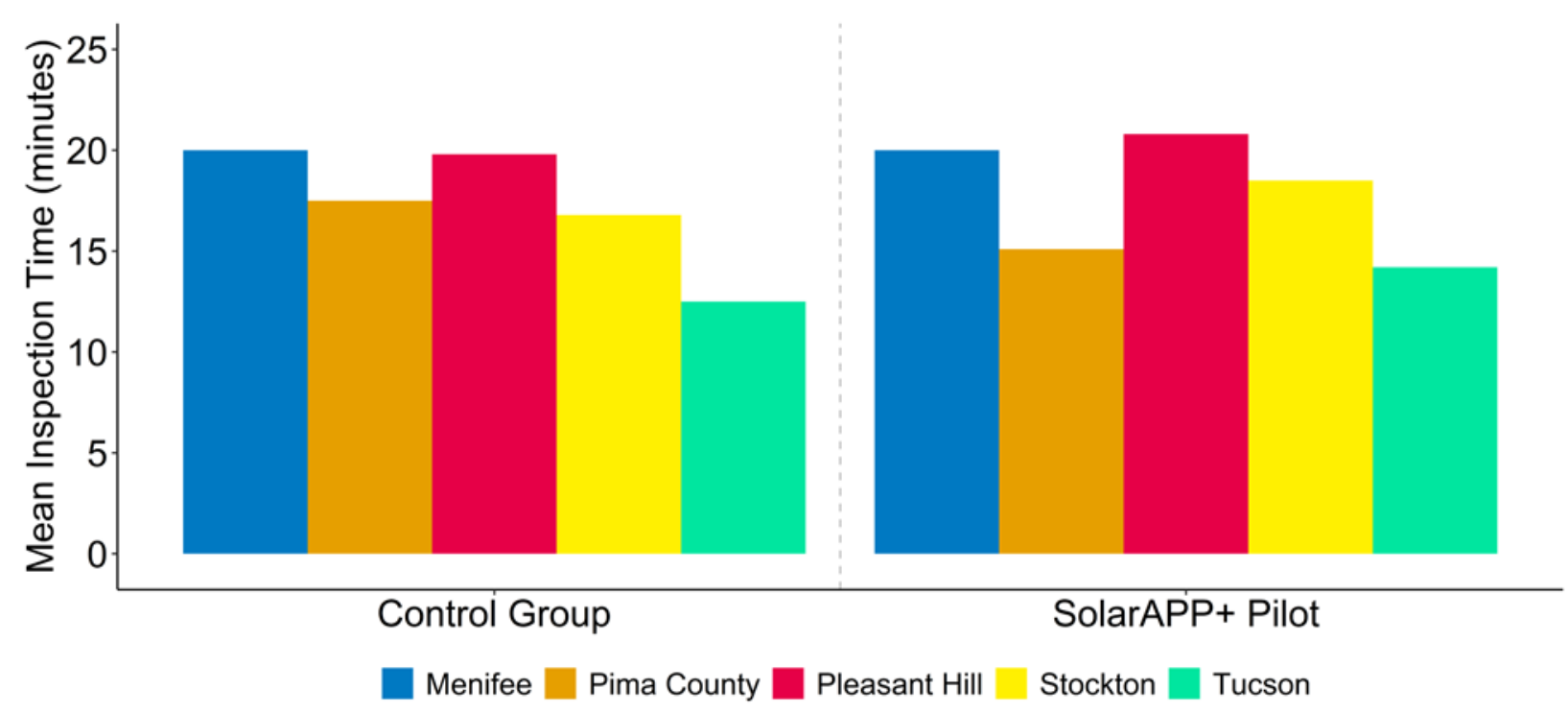

Figure 6. Mean inspection duration for control and SolarAPP+ projects

\subsection{Solar Adoption Timeline Impacts}

The prior two sections discussed the impacts of the SolarAPP + on specific stages of the residential solar permit process. This section considers the full timeline impacts of the SolarAPP+ from permit submittal to final inspection. In comparison to both historical trends and the control projects, SolarAPP+ projects were installed and passed inspection in fewer days, as shown in Figure 7. 


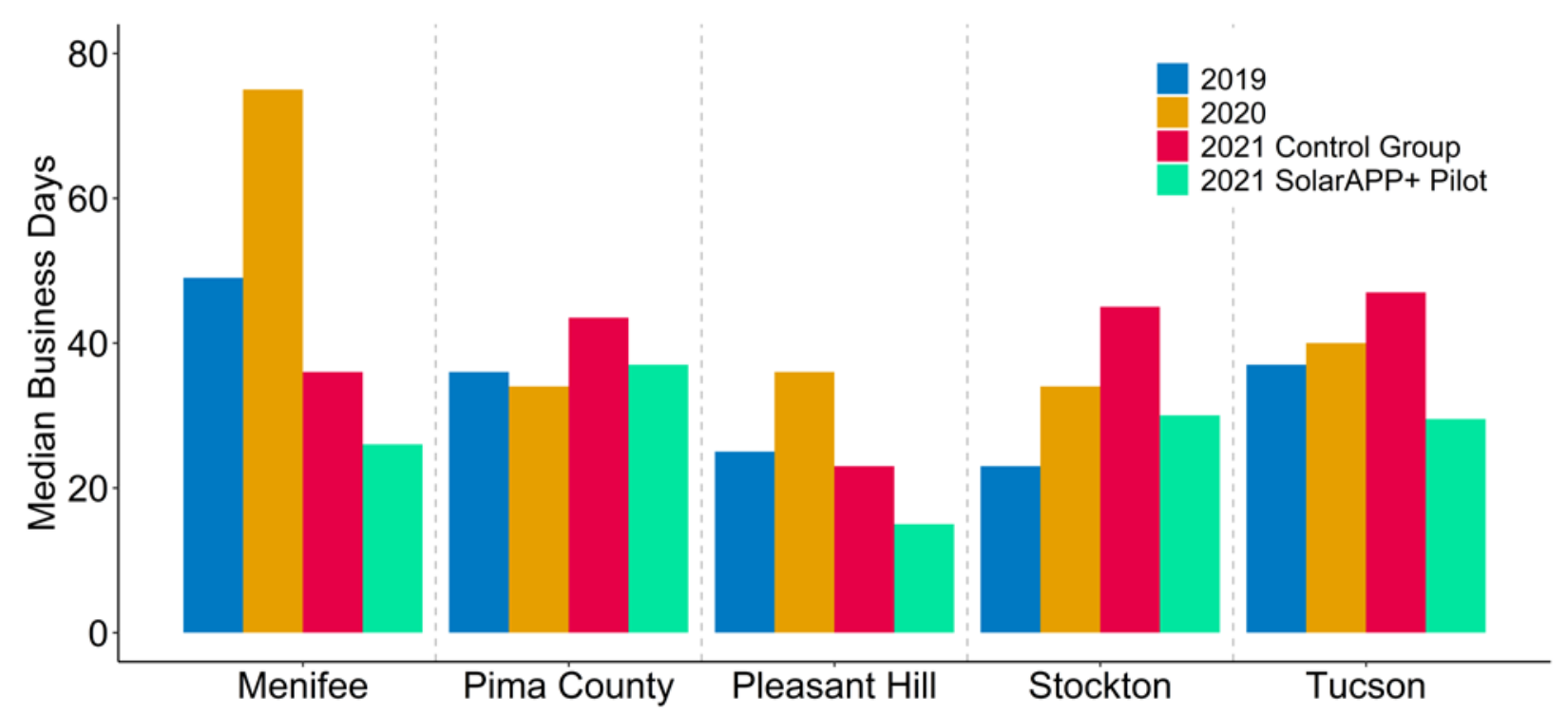

Figure 7. Median project time from permit submission to passed inspection

Compared to the control group, SolarAPP+ projects required fewer total days for completion, with time savings ranging from 6.5 days for Pima County to 17.5 days for Tucson. Across all pilot AHJs, the average project time savings were 12 days. The total project time savings for Menifee, Pima County, Pleasant Hill, and Stockton were larger than the time savings attributable to the permit review stage, suggesting that the SolarAPP + resulted in other procedural efficiencies in those jurisdictions. Conversely, the total project time savings for Tucson were smaller than the time savings attributable to the permit review stage, suggesting that the efficiencies of the SolarAPP + were countered by other factors in that jurisdiction, such as utility interconnection reviews.

\subsection{AHJ Time Savings}

The primary goal of the SolarAPP+ is to address AHJ permitting resource constraints. AHJs were still required to invest human resources in the development and implementation of the pilots, including software integration, finance alignment, data collection, and pilot meetings. Data collection from the pilot was used to identify whether AHJ time investment in piloting SolarAPP + was recouped through staff time savings during or following the pilot. The time spent implementing the SolarAPP + and the time savings associated with permit and revision review during the pilot period are summarized in Table 7. 
Table 7. Estimated AHJ Permit and Revision Review Time Savings During Pilot, in Hours

\begin{tabular}{l|c|cccc|c}
\hline AHJ & $\begin{array}{c}\text { Time Spent on } \\
\text { SolarAPP+ } \\
\text { Implementation }\end{array}$ & $\begin{array}{c}\text { Review } \\
\text { Savings } \\
\text { per } \\
\text { SolarAPP+ } \\
\text { Permit }\end{array}$ & $\begin{array}{c}\text { Permit } \\
\text { Review } \\
\text { Savings }\end{array}$ & $\begin{array}{c}\text { Revision } \\
\text { Savings } \\
\text { per } \\
\text { SolarAPP+ } \\
\text { Permit }\end{array}$ & $\begin{array}{c}\text { Revision } \\
\text { Review } \\
\text { Savings }\end{array}$ & $\begin{array}{c}\text { Total Time } \\
\text { Savings^ }\end{array}$ \\
\hline Menifee & 41.5 & 0.42 & 10.9 & 0.33 & 1 & 12 \\
$\begin{array}{l}\text { Pima } \\
\text { County }\end{array}$ & 153 & 1 & 55 & 0.75 & 36 & 91 \\
\hline $\begin{array}{l}\text { Pleasant } \\
\text { Hill }\end{array}$ & 20 & 0.25 & 4.5 & 0.20 & 2.6 & 7 \\
Stockton & 68 & 0.28 & 14 & 0.25 & 6.5 & 21 \\
\hline Tucson & 100 & 1 & 73 & 0.75 & 31.5 & 105 \\
\hline Total & $\mathbf{3 8 2 . 5}$ & - & $\mathbf{1 5 7 . 4}$ & - & $\mathbf{7 7 . 6}$ & $\mathbf{2 3 6}$ \\
\hline
\end{tabular}

$\wedge$ Totals may not be exact due to rounding.

Combined, the five AHJs spent an estimated 383 hours on SolarAPP + implementation activities, including SolarAPP+ integration, data collection, and weekly meetings during the pilot.

Collectively, the AHJs saved 236 hours during the pilot, resulting in a collective net loss of time during the pilot period, with only Tucson recouping its implementation time investment during that period. Since the pilot period closed, each AHJ continues to experience time savings. Table 8 shows the AHJ time savings for projects submitted through the SolarAPP+ post-pilot through December 3, 2021, as well as the cumulative time savings from the pilot and post-pilot stages.

Table 8. Estimated AHJ Permit and Revision Review Time Savings Post-Pilot Through December 3, 2021, in Hours

\begin{tabular}{l|cccc|c|c}
\hline AHJ & $\begin{array}{c}\text { Review } \\
\text { Savings } \\
\text { per Permit }\end{array}$ & $\begin{array}{c}\text { Permit } \\
\text { Review } \\
\text { Savings }\end{array}$ & $\begin{array}{c}\text { Revision } \\
\text { Savings } \\
\text { per Permit }\end{array}$ & $\begin{array}{c}\text { Revision } \\
\text { Review } \\
\text { Savings }\end{array}$ & $\begin{array}{c}\text { Post-Pilot } \\
\text { Total Time } \\
\text { Savings }\end{array}$ & $\begin{array}{c}\text { Cumulative } \\
\text { Time } \\
\text { Savings }\end{array}$ \\
\hline Menifee & 0.42 & 174.3 & 0.33 & 39 & 213 & 225 \\
Pima County & 1 & 558 & 0.75 & 81 & 639 & 730 \\
\hline Pleasant Hill & 0.25 & 6.5 & 0.20 & 2.4 & 9 & 16 \\
Stockton & 0.28 & 16.8 & 0.25 & 1.5 & 18 & 39 \\
\hline Tucson & 1 & 1,440 & 0.75 & 189.75 & 1,630 & 1,735 \\
\hline Total & - & $\mathbf{2 , 1 9 5 . 6}$ & - & $\mathbf{3 1 3 . 7}$ & $\mathbf{2 , 5 0 9}$ & $\mathbf{2 , 7 4 5}$ \\
\hline
\end{tabular}

$\wedge$ Totals may not be exact due to rounding.

Post-pilot, each AHJ made the SolarAPP+ available to all contractors in their jurisdictions, and through December 3, 2021, 2,499 additional permits and 497 revisions were submitted through SolarAPP + . Cumulatively through December 3, 2021, SolarAPP + has saved these AHJs over 2,700 combined staff hours, in comparison to less than 400 spent for SolarAPP+ implementation. Time savings continue to vary by community. Three of the five AHJs have subsequently saved more time on SolarAPP+ permits than their time investment to implement SolarAPP+, with Pleasant Hill and Stockton expected to recoup their time investments soon. 


\section{SolarAPP+ Pilot Lessons Learned}

The five pilot jurisdictions generated numerous lessons learned that resulted in product improvements throughout the evaluation period. We do not summarize every lesson here, but rather focus on the most significant findings including those related to software integration, adoption process, training needs, product expansion, permitting fees, and overall timeline impacts.

\subsection{Software Integration}

Most local governments have some type of permitting software, either a desktop (internal) system or an online (public-facing) system. The SolarAPP+ was designed to serve both types of communities, through the stand-alone and software integrated pathways, respectively. Both configurations were tested in the pilot, with varying implementation requirements and timelines. Additionally, SolarAPP + can also benefit AHJs that do not currently utilize permitting software.

Version 1 of the software-integrated approach was the most common adoption pathway used in the pilot, which continues to be the case with subsequent adopters. Tucson and Pima County, Arizona, were the first two to adopt this approach, requiring the development of an instant permitting process from scratch within Pima County's Accela Citizen Access (ACA) portal. ${ }^{15}$ This required several meetings to define and scope, followed by an estimated 53 hours of software development and testing time.

To reduce software development time for other communities, the SolarAPP+ team worked with Accela and other software developers to develop a downloadable template that could help reduce software development time. Subsequently, Menifee and Stockton, California, used the Accela template as a baseline to configure their own ACA platforms. These templates are not a one-sizefits-all system, as communities often have their own unique permit requirements and related fees that must still be configured within the system. Even so, Menifee and Stockton were able to implement a software integration in an estimated 15 to 40 hours, representing $20 \%$ to $72 \%$ time savings from the first use case.

Pleasant Hill, California, was the only community to adopt Version 2 or the stand-alone version during the pilot. That approach requires no software development time but does require the community to adopt the SolarAPP+-provided online payment platform. Enabling online payments via the platform and configuring the rest of the system in Pleasant Hill took an estimated 8 hours. Though this approach takes less time to set up, some communities have been apprehensive to enable the online payment process, given it requires additional accounting. In addition, Pleasant Hill is in the process of implementing a new public-facing permitting software and will be transitioning to the software integrated approach after that implementation. Thus, this approach may more commonly be used as an interim measure than a preferred approach by communities adopting the SolarAPP+.

\footnotetext{
${ }^{15}$ Beginning in mid-2021 and through the SolarAPP+ pilot, Pima County processed permits for Tucson.
} 


\subsection{Adoption Process}

Preparing for and implementing SolarAPP + , required numerous meetings to identify which software adoption approach would be most appropriate among other considerations. Within these meetings, it became apparent that some of the process could be automated to allow communities to evaluate and select their adoption pathway without the need for meetings with the SolarAPP+ team. As a result, a new web-based onboarding process was developed that asks the local government to answer a series of questions prior to signaling their interest. Once a community signals their interest in adoption, all the required software features and implementation processes are in place to allow for swift use of the SolarAPP + in the interested community.

\subsection{Training Resources}

The SolarAPP+ incorporates a fundamentally new permitting process that requires contractors to answer a set of questions they are not typically required to answer during a traditional permit application process. At the same time, the SolarAPP + generates a novel inspection checklist that translates the inputs of the contractor into an itemized list for the inspector to verify in the field, which is different from the traditional diagram-driven plan-sets they typically use to inspect. It became clear in the early pilot implementation that training would be beneficial for contractors and inspectors to understand and effectively navigate the new SolarAPP+ process.

NREL initially conducted virtual trainings directly with inspectors and contractors to answer questions regarding the new SolarAPP + process. With feedback from initial trainings, two online, public-facing trainings were developed and published in partnership with the Interstate Renewable Energy Council, covering how to enter a rooftop solar project design into the SolarAPP+ and how to inspect a SolarAPP+-approved rooftop solar project. These trainings are promoted to both inspectors and contractors to ensure that contractors know what to expect at the time of inspection and that inspectors understand how the checklist is generated from the contractor inputs. ${ }^{16}$ Subsequent trainings are planned for new product expansions, including solar and storage, to ensure that contractors and inspectors understand how to efficiently use the SolarAPP+.

\subsection{Product Expansion}

The SolarAPP+ was initially designed with the intent to cover $80 \%$ to $90 \%$ of residential rooftop solar projects, with the knowledge that some projects would be too complex for the first version of the SolarAPP+ to approve, such as those systems using two different module types or adding capacity to existing systems.

Feedback from contractors and local government personnel identified multiple product feature enhancements that could expand the scope of SolarAPP+ eligible systems. Some of the most significant improvements that resulted in increased project volume during the pilot include:

- Allowing Main Panel Upgrades: where the contractor must install a new, typically larger main electric service panel to accommodate the solar project.

\footnotetext{
${ }^{16}$ Both trainings can be viewed here: https://cleanenergytraining.org/.
} 
- Allowing Main Breaker Derates: where the contractor wishes to reduce the main electric service breaker amperage rating to accommodate the solar project.

- Expanding Eligible Roof Coverings: SolarAPP+ initially artificially constrained qualifying roof coverings.

- Expanding Point of Interconnection Methods: SolarAPP+ implemented software expansion to allow new interconnection options, including supply-side interconnections.

The pilot also signaled the importance of developing functionality to process combined solar and storage products. SolarAPP + was initially developed to process stand-alone residential solar projects, but during the pilot process, contractors and AHJs noted that this project type was seeing significant market growth, especially in the California communities. Several contractors indicated that solar and storage systems were exceeding $50 \%$ of their project volume. With this feedback, the SolarAPP+ team began developing and incorporating this functionality into SolarAPP + , but it was not fully completed by the conclusion of the pilot.

\subsection{Permitting Fees}

The SolarAPP+ replaces the plan review process in both the stand-alone and software adoption approaches, which would have previously been completed by the AHJ. Given that contractors are required to pay a $\$ 25$ SolarAPP+ fee to get an approved plan, and the local government was no longer performing plan review, Pima County and Tucson, Arizona, both decided to adjust their permit fees for SolarAPP+ projects to remove the plan review portion of the fee. This resulted in a net permit fee reduction of \$6 per project submitted via the SolarAPP, accounting for the SolarAPP+ fee. Other piloting communities plan to review their permit fees for SolarAPP+ projects in upcoming regularly scheduled permit fee reviews. These fee review processes may result in similar changes to fees that could result in more net permit fee savings.

\subsection{Overall Install Timeline Impacts}

The SolarAPP+ was designed to streamline permitting, with the goal to identify pathways to streamline the entire solar adoption process, from contract signature to commissioning of the system. As noted, the SolarAPP+ projects have ultimately been installed and inspected faster than the control group, showing that savings during the permitting process can result in projects being completed faster, to the benefit of adopting customers. Though it is not possible to identify the specific factors that caused the demonstrated improvement, piloting contractors have stated that permitting certainty allows the contractor to schedule their installation pipeline more easily.

The adoption of the SolarAPP+ has also had complimentary benefits to streamline process requirements. Pima County and Tucson, Arizona, are both served by Tucson Electric Power. These two communities worked with the SolarAPP+ team and Tucson Electric Power to streamline the preapproval to build interconnection application requirements for contractors. ${ }^{17}$

\footnotetext{
17 The streamlined interconnection application requirements are summarized here: https://webcms.pima.gov/cms/One.aspx?portalId=169\&pageId=181230.
} 


\section{Conclusion}

The SolarAPP + pilot demonstrated the functionality of the SolarAPP + and showcased the value of the platform to all stakeholders. The key findings of this work are as follows:

- Pilot AHJs collectively spent 383 hours on SolarAPP+ implementation and saved 236 hours on permit and revision review during the course of the pilot.

- By providing instantaneous review, the SolarAPP+ reduced the average permit review time to less than one day across all five AHJs.

- Participating contractors required training on how to use the application efficiently.

- Inspection passage rates for SolarAPP+ projects were comparable to those of traditionally permitted projects, and there were nominal impacts on inspection duration.

- Projects submitted through SolarAPP+ were installed and inspected on average 12 days faster than projects using the traditional process (Figure ES- 1).

Following the pilot, the AHJs rolled out SolarAPP+ to all local contractors, not just the contractors participating in the pilot. From the Pilot Closure to New Permits date through December 3, 2021, the AHJs saved more than 2,500 additional staff hours on permit and revision review.

Beyond these clear benefits, implementation of the SolarAPP + also identified various areas to improve the product and meet $\mathrm{AHJ}$ and contractor needs. These areas include finding new and innovative pathways to reduce software integration timelines, further streamlining AHJ onboarding, providing new product features such as the ability to permit solar and storage systems, and developing associated trainings for these and existing features. These results and developments can provide interested AHJs with the information needed to determine whether the SolarAPP+ is appropriate for their jurisdiction. 


\section{References}

Burkhardt, J., Wiser, R., Darghouth, N., Dong, C.G., Huneycutt, J., 2015. "Exploring the impact of permitting and local regulatory processes on residential solar prices in the United States."

Energy Policy 78, 102-112. https://doi.org/10.1016/j.enpol.2014.12.020.

Cook, J.J., Cruce, J., O’Shaughnessy, E., Ardani, K., Margolis, R., 2021a. "Exploring the link between project delays and cancelation rates in the U.S. rooftop solar industry." Energy Policy 156, 112421. https://doi.org/10.1016/j.enpol.2021.112421

Cook, J.J., Cruce, J.R., Fekete, E., Dong, S. (Sara), 2021b. Solar permitting, inspection, and interconnection cycletimes and requirements (dataset). National Renewable Energy Laboratory (NREL).

Davis, M., White, B., Goldstein, R., Sun, X., Cox, M., Manghani, R., Rumery, S., Silver, C., Baca, J., 2021a. Q2 2021 U.S. Solar Market Insight report. Wood Mackenzie \& Solar Energy Industries Association (SEIA).

Davis, M., White, B., Smith, C., Goldstein, R., Sun, X., Cox, M., Curtin, G., Manghani, R., Rumery, S., Silver, C., Baca, J., 2021b. U.S. Solar Market Insight - 2020 Year in Review. Wood Mackenzie \& Solar Energy Industries Association (SEIA).

Dong, C., Wiser, R., 2013. "The impact of city-level permitting processes on residential photovoltaic installation prices and development times: An empirical analysis of solar systems in California cities." Energy Policy 63, 531-542. https://doi.org/10.1016/j.enpol.2013.08.054

Feldman, D., Ramasamy, V., Fu, R., Ramdas, A., Desai, J., Margolis, R., 2021. U.S. Solar Photovoltaic System and Energy Storage Cost Benchmark: Q1 2020. National Renewable Energy Laboratory (NREL), Golden, CO.

Hsu, J.H.-Y., 2018. "Predictors for adoption of local solar approval processes and impact on residential solar installations in California cities." Energy Policy 117, 463-472.

https://doi.org/10.1016/j.enpol.2018.03.008

NREL, 2021. SolarTRACE [WWW Document]. solarapp.nrel.gov. URL https://solarapp.nrel.gov/solarTRACE (accessed 7.1.21).

O'Shaughnessy, E., Barbose, G., Wiser, R., 2020. "Patience is a virtue: A data-driven analysis of rooftop solar PV permitting timelines in the United States." Energy Policy 144, 111615. https://doi.org/10.1016/j.enpol.2020.111615

O’Shaughnessy, E., Dong, S., Cook, J.J., Cruce, J., Ardani, K., Fekete, E., Margolis, R., 2022. "Effects of local permitting and interconnection requirements on solar PV installation durations." Energy Policy 161, 112734. https://doi.org/10.1016/j.enpol.2021.112734

O’Shaughnessy, E., Nemet, G.F., Pless, J., Margolis, R., 2019. "Addressing the soft cost challenge in U.S. small-scale solar PV system pricing." Energy Policy 134, 110956. https://doi.org/10.1016/j.enpol.2019.110956 
Parsons, S., Josefowitz, N., 2021. A No-Cost Rooftop Solar Stimulus. SPUR, San Francisco, CA.

Sinitskaya, E., Gomez, K.J., Bao, Q., Yang, M.C., MacDonald, E.F., 2019. "Designing linked journey maps to understand the complexities of the residential solar energy market." Renewable Energy 145, 1910-1922. https://doi.org/10.1016/j.renene.2019.06.018

Stanfield, S., Kapla, K., McConnell, E.S., Haynes, R., Kooles, K., 2013. Minimizing Overlap in PV System Approval Processes. Interstate Renewable Energy Council (IREC).

Stanfield, S., Schroeder, E., Culley, T., 2012. Sharing Success: Emerging Approaches to Efficient Rooftop Solar Permitting. Interstate Renewable Energy Council (IREC).

White, L.V., 2019. "Increasing residential solar installations in California: Have local permitting processes historically driven differences between cities?" Energy Policy 124, 46-53.

https://doi.org/10.1016/j.enpol.2018.09.034

Wolske, K.S., Gillingham, K.T., Schultz, P.W., 2020. "Peer influence on household energy behaviours." Nat Energy 5, 202-212. https://doi.org/10.1038/s41560-019-0541-9 


\section{Appendix A. SolarAPP+ Pilot Data Collection}

The following data fields were collected from participating AHJs during the pilot:

- Reviewing staff name

- Project address

- Project ID (if different from address)

- Project size

- Project contractor

- Submission date

- Submission type (SolarAPP+ or Traditional)

- Number of staff involved in permit review

- Traditional project:

○ Time required to review permit (hours)

○ Was permit rejected as submitted?

○ Date of rejection (if applicable)

○ Cause of rejection (if applicable)

- Date of initial approval

○ Were there revisions to the project following initial approval?

- Revision submittal date

○ Time required to review revisions following initial approval (hours)

○ Were revisions rejected?

○ Date of rejection (if applicable)

○ Cause of rejection (if applicable)

- Revision review completion date

○ How many rounds of revision were completed?

○ Final approval date.

- Inspection date

- Inspection duration (hours)

- Inspection result

- Cause of inspection failure (if applicable)

- Number of inspections required to pass

- Notes. 
The following data fields were collected from participating contractors during the pilot:

- Staff name

- Project address

- Project ID (if different from address)

- Project size

- AHJ

- Submission date

- Submission type (SolarAPP+ or Traditional)

- Number of staff involved in permit review

- Time required for permit preparation/design (hours)

- Time required process to submit permit (hours)

- SolarAPP+ projects:

○ Did SolarAPP+ reject the initial submission?

- Cause of rejection (if applicable).

- Traditional projects:

○ Was permit rejected after submission?

- Cause of rejection (if applicable)

- Time required to revise rejected submission (hours).

- Initial approval date

- Were there revisions to the project following initial approval?

- Revision submittal date

- Time required to design/prepare revisions (hours)

- Time required to submit revisions (hours)

- What prompted the need for revision?

- Were revisions rejected?

- Revision approval date

- Cause of rejection (if applicable)

- How many rounds of revision were completed?

- Final approval date

- Inspection date

- Inspection duration (minutes) 
- Inspection result

- Was a technician required to attend the inspection?

- Were on-site SolarAPP+ permit revisions required during the inspection?

- Cause of inspection failure (if applicable)

- Does utility require a plan set or line drawings for interconnection approval?

- Utility interconnection submittal date (if applicable)

- Utility interconnection approval date (if applicable)

- Notes. 